\title{
$\frac{10}{4-4}-9795(1)$
}

SANDIA REPORT

SAND97-8223 • UC-405

$M 97052387$

Unlimited Release

* Printed January 1997

\section{Thermodynamic Cycle Analysis Program (TCAP)}

\author{
A. S. Yoshimura
}

? Prepared by

Sandia National Laboratories

Albuquerque, New Mexico 87 185 and livermore, California 94551 for the United States Department of Energy

under Contract DE-AC04-94AL85000

- Approved for public release; dișth buthton is unlimited.

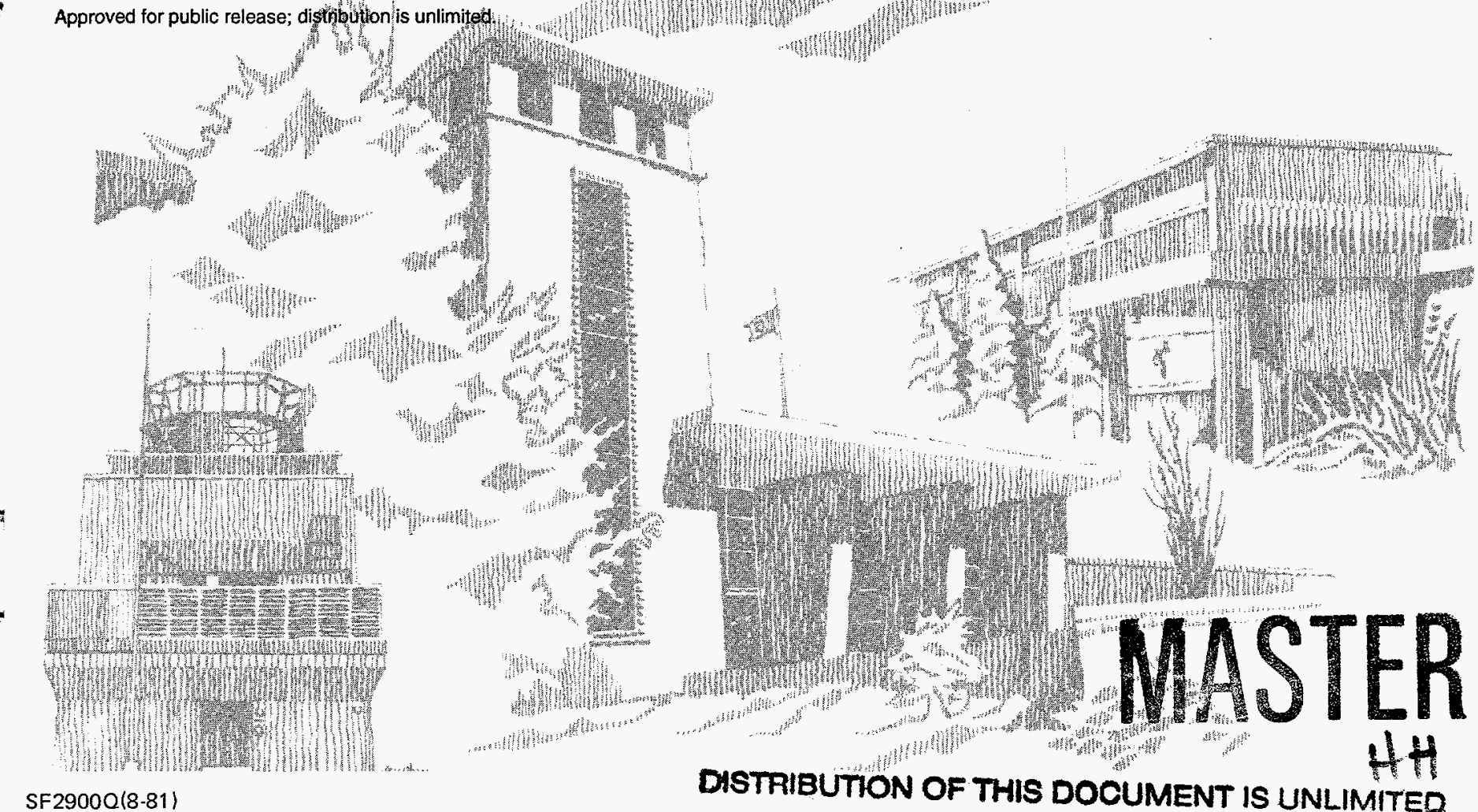


Issued by Sandia National Laboratories, operated for the United States Department of Energy by Sandia Corporation.

NOTICE: This report was prepared as an account of work sponsored by an agency of the United States Government. Neither the United States Government nor any agency thereof, nor any of their employees, nor any of the contractors, subcontractors, or their employees, makes any warranty, express or implied, or assumes any legal liability or responsibility for the accuracy, completeness, or usefulness of any information, apparatus, product, or process disclosed, or represents that its use would not infringe privately owned rights. Reference herein to any specific commercial product, process, or service by trade name, trademark, manufacturer, or otherwise, does not necessarily constitute or imply its endorsement, recommendation, or favoring by the United States Government, any agency thereof or any of their contractors or subcontractors. The views and opinions expressed herein do not necessarily state or reflect those of the United States Government, any agency thereof, or any of their contractors or subcontractors.

This report has been reproduced from the best available copy.

Available to DOE and DOE contractors from:

Office of Scientific and Technical Information

P.O. Box 62

Oak Ridge TN 37831

Prices available from (615) 576-8401, FTS 626-8401.

Available to the public from:

National Technical Information Service

U.S. Department of Commerce

5285 Port Royal Rd.

Springfield, VA 22161 


\section{DISCLAIMER}

This report was prepared as an account of work sponsored by an agency of the United States Government. Neither the United States Government nor any agency thereof, nor any of their employees, make any warranty, express or implied, or assumes any legal liability or responsibility for the accuracy, completeness, or usefulness of any information, apparatus, product, or process disclosed, or represents that its use would not infringe privately owned rights. Reference herein to any specific commercial product, process, or service by trade name, trademark, manufacturer, or otherwise does not necessarily constitute or imply its endorsement, recommendation, or favoring by the United States Government or any agency thereof. The views and opinions of authors expressed herein do not necessarily state or reflect those of the United States Government or any agency thereof. 


\section{DISCLAMMER}

Portions of this document may be illegible in electronic image products. Images are produced from the best available original document. 
SAND97-8223

Unlimited Release

Printed January 1997

Distribution

Category UC-405

\title{
Thermodynamic Cycle Analysis Program (TCAP)
}

\author{
Ann S. Yoshimura \\ Systems Research Department \\ Sandia National Laboratories \\ Livermore, CA 94551
}

\begin{abstract}
This report describes the Thermodynamic Cycle Analysis Program (TCAP) software developed in support of the Collaborative Advanced Gas Turbine (CAGT) research project. The goal of the CAGT project was to evaluate different configurations of gas turbine-based power generation cycles. TCAP software enables the user to graphically construct power cycles that incorporate a variety of components such as compressors, turbines, heat exchangers, and reactors. The user also specifies the input condition of the working fluid and the parameters associated with each component. TCAP then calculates the composition and thermodynamic properties of the working fluid at every point in the cycle. From this data, TCAP calculates the overall thermodynamic efficiency of the cycle and emission levels of specific chemicals. Thermodynamic and chemical kinetic data are based on the Chemkin family of application codes and libraries.
\end{abstract}




\section{Acknowledgments}

The author thanks A. E. Lutz of the Mechanics and Simulation of Manufacturing Processes Department for his contributions in interfacing the TCAP software with Chemkin applications and libraries, and P. K. Falcone of the Systems Studies Department for her leadership in Sandia's support of the CAGT Project. 


\section{Thermodynamic Cycle Analysis Program (TCAP)}

\section{Introduction}

The Collaborative Advanced Gas Turbine (CAGT) project was launched in 1992 by the California Energy Commission and several power utilities, including the Pacific Gas and Electric Company. The goal of the project was to evaluate several proposed configurations for gas turbine-based power generation cycles. Two of the key metrics were (1) thermodynamic efficiency and (2) the level of NOx and SOx emissions produced. Several commercial tools that calculate thermodynamic efficiencies of power cycles were available. However, these programs were limited to modeling non-reacting fluids or fluids always in a state of chemical equilibrium. They could not predict emission levels produced by chemical reactions in a combustor in the cycle.

We developed the Thermodynamic Cycle Analysis Program (TCAP) to provide the capability of predicting emission levels as well as thermodynamic efficiency. This required the incorporation of chemical kinetics modeling as well as equilibrium thermodynamic property modeling.

This report describes the design and functionality of the TCAP software.

\section{Cycle Construction}

In TCAP, power cycles are composed of components and connections. Components represent turbines, compressors, combustors, and other physical parts of the power generation cycle. Each type of component has a variable number of parameters that describe its behavior. For example, a turbine component has three parameters: the number of effective stages, the pressure ratio, and the isentropic efficiency. A complete list of components is given in the Appendix.

A connection links two components together and can be one of three types: fluid, work, or heat. A fluid connection represents the flow of fluid from the outlet of one component to the inlet of the other. A work connection represents the transfer of mechanical work from one component to another (e.g. from a turbine to a compressor). A heat connection represents the transfer of sensible heat from one component to another (e.g. from a combustor to a heater).

Fluid connections represent the working fluid of the cycle. The fluid is characterized by its composition (a list of chemical species and their relative amounts), its flowrate, and its 
thermodynamic properties (temperature, pressure, enthalpy, and entropy). Work connections are characterized by the work rate (power) being transferred; heat connections by the heat rate.

TCAP is extremely flexible in its support of cycle configurations: cycles can be composed of any combination of any number of components. There is also no limit to the number of connections in a cycle, although individual components may restrict the number and type of connections that can be linked to it. For example, a turbine must have one inlet fluid stream and one outlet fluid stream, and may have one outgoing work connection. A heater must have one inlet fluid stream and one outlet stream, and may have an incoming heat connection (the incoming heat energy is transferred to the fluid flowing through the heater).

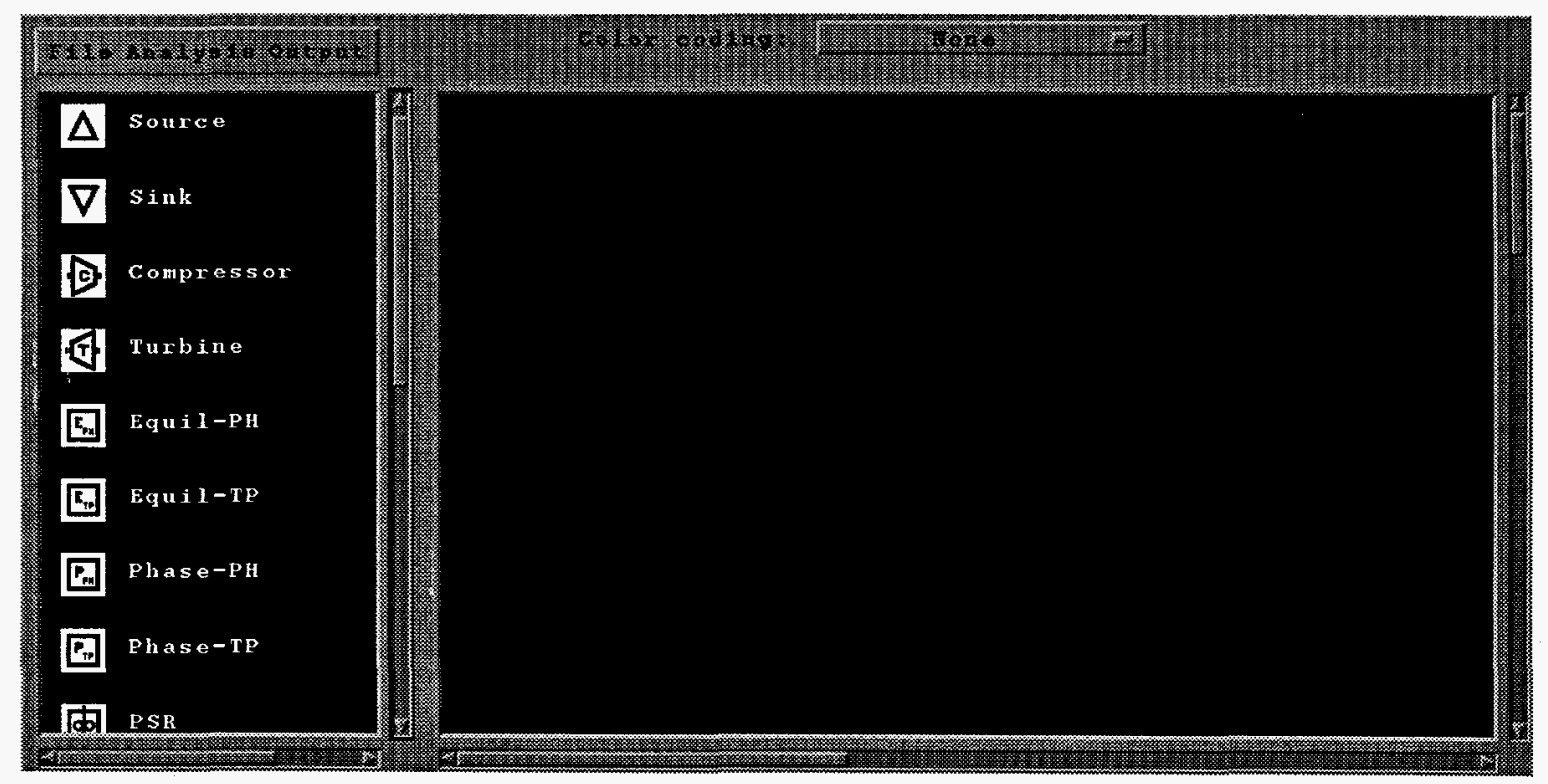

Figure 1. The main window of TCAP's graphical user interface.

Cycles are constructed using TCAP's graphical user interface. The main window comprises two sections: a palette of components and a drawing area (Figure 1). On the palette are icon representations of all of the components that can be modeled. To add a component to the cycle, the user clicks on the appropriate icon, then places it on the drawing area. Clicking on the placed icon brings up another window that displays the parameters associated with the component. In this window, values for each of the parameters may be entered or edited by the user. This is illustrated in Figure 2 for a Turbine. 


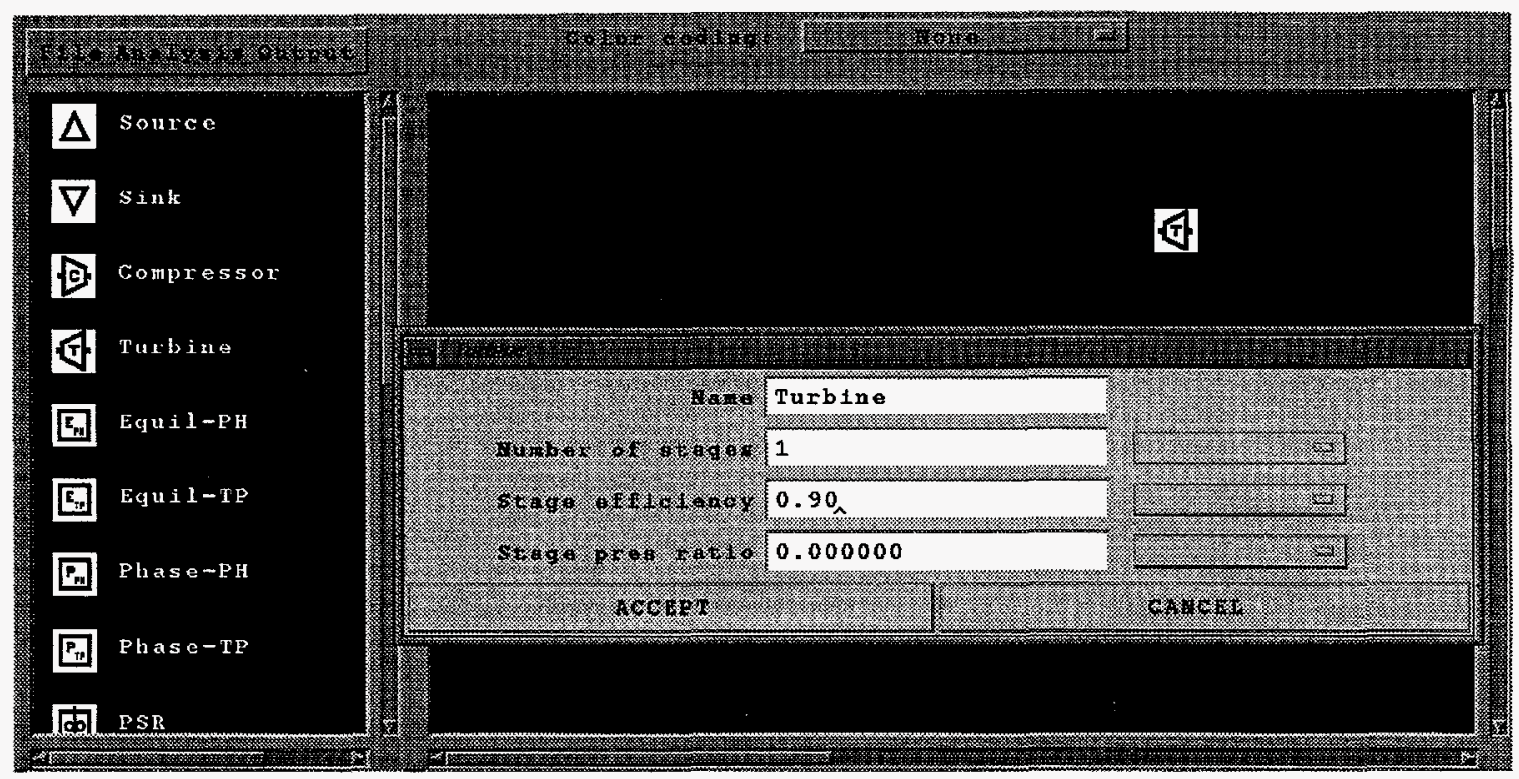

Figure 2. Editing window for a component.

All three types of connections are created by first specifying the source component, then the destination component for the fluid, work, or energy stream. Once the connection is created, clicking on it brings up a window that displays the associated thermodynamic properties or parameters. As with components, values of the properties or parameters may be entered or edited by the user. This is illustrated in Figure 3 for a fluid connection.

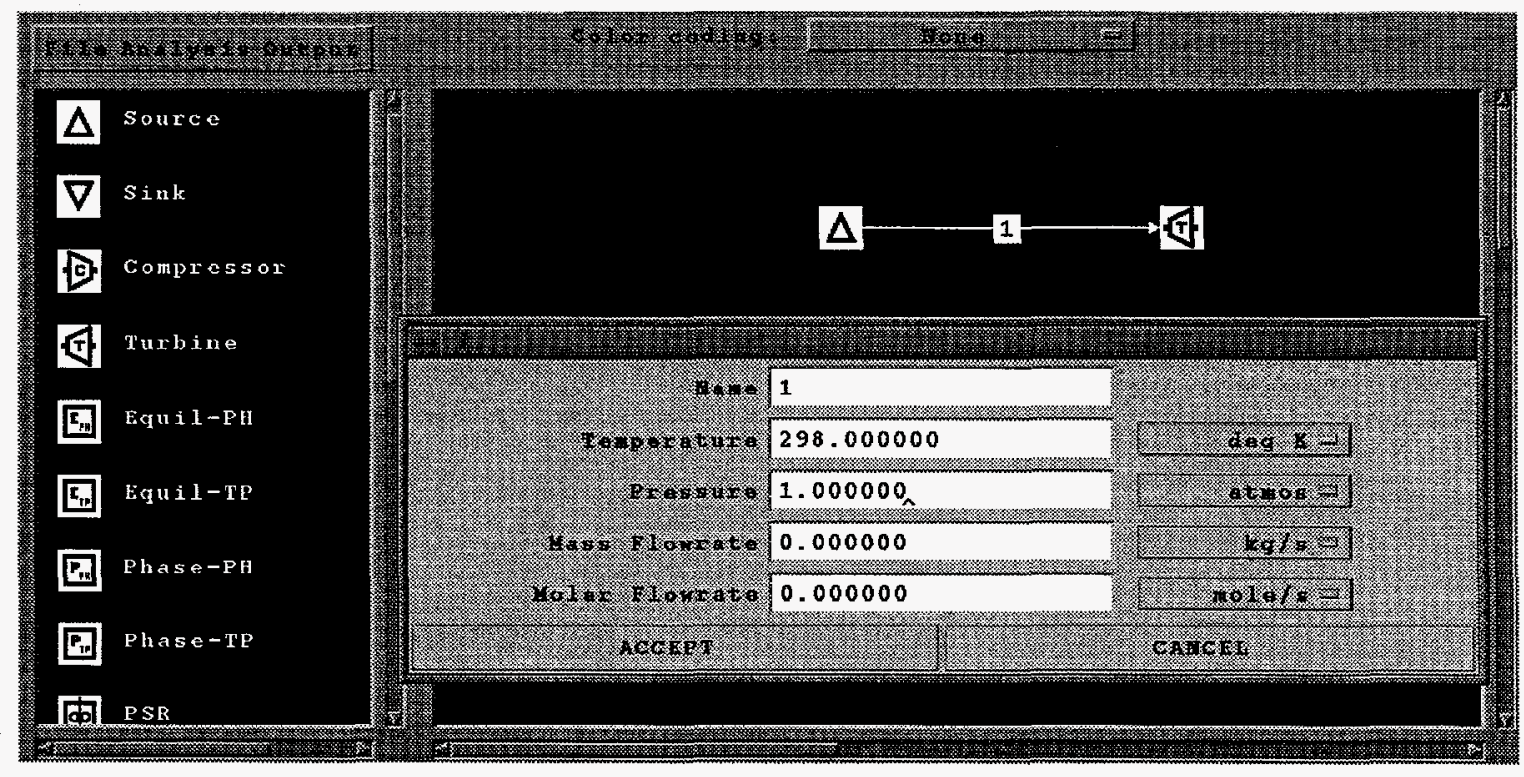

Figure 3. Editing window for a fluid connection.

An example of a completed cycle is shown in Figure 4. This is a very basic cycle configuration in which the working fluid emerges from a fluid source and is compressed, 
heated, and expanded through a turbine before it enters a fluid sink. The following properties and parameters have been specified for the cycle:

$\begin{array}{lll}\text { Fluid state 1: } & \text { composition } & \text { air }\left(78 \% \mathrm{~N}_{2}, 21 \% \mathrm{O}_{2}, 1 \% \mathrm{Ar}\right) \\ & \begin{array}{l}288 \mathrm{~K} \\ \text { temperature } \\ \text { pressure } \\ \text { mass flowrate }\end{array} & \begin{array}{l}1 \text { atmosphere } \\ 1 \text { kilogram/second }\end{array} \\ & & 1 \\ \text { Compressor: } & \text { number of stages } & 12 \\ & \begin{array}{l}\text { pressure ratio per stage } \\ \text { isentropic efficiency }\end{array} & 0.87 \\ \text { Fluid state 3: } & \text { temperature } & 1400 \mathrm{~K} \\ \text { Turbine: } & \begin{array}{l}\text { number of stages } \\ \text { isentropic efficiency }\end{array} & 1 \\ \text { Fluid state 4: } & \text { pressure } & 0.95\end{array}$

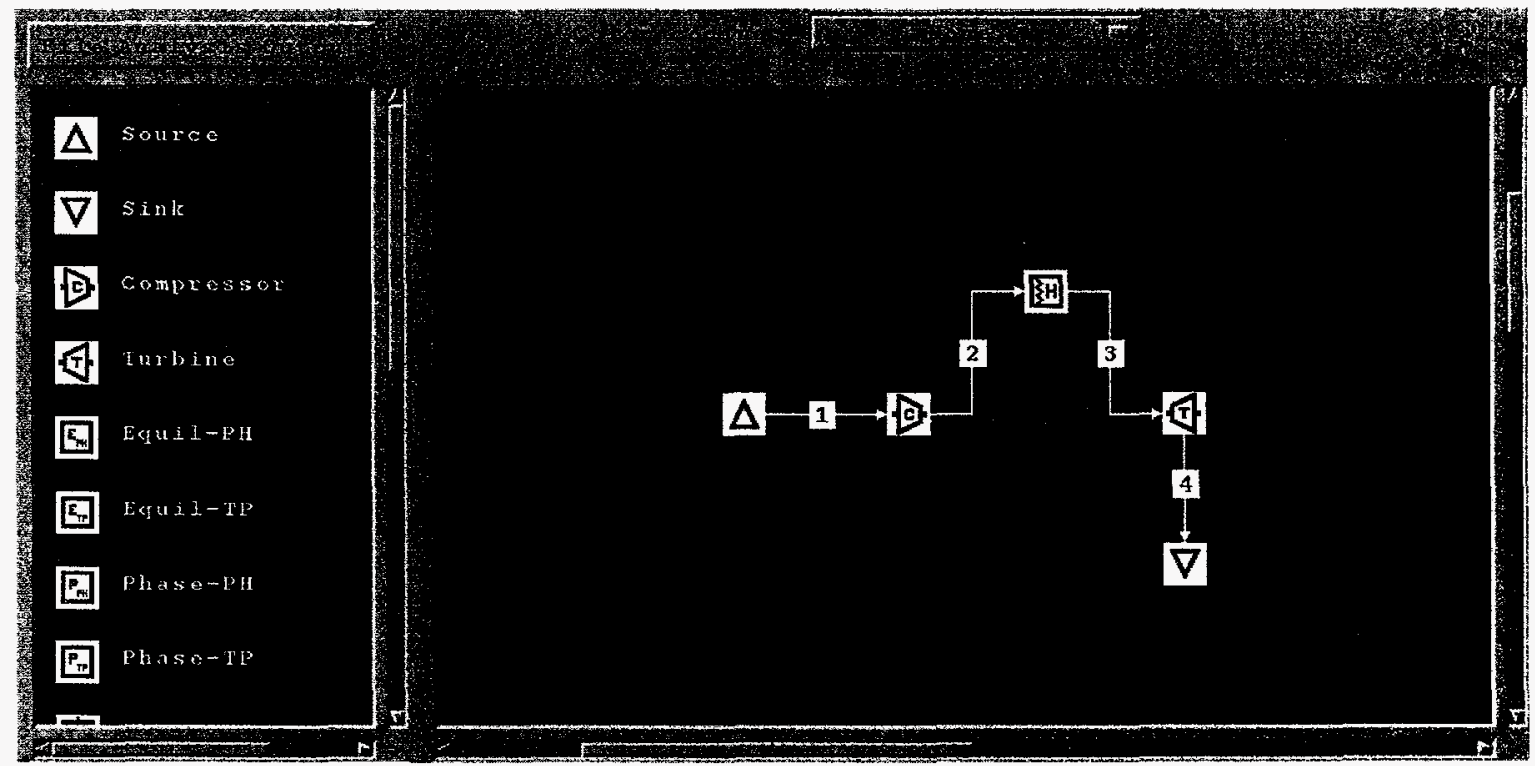

Figure 4. A basic air cycle.

An example of a more complex cycle configuration is shown in Figure 5. 


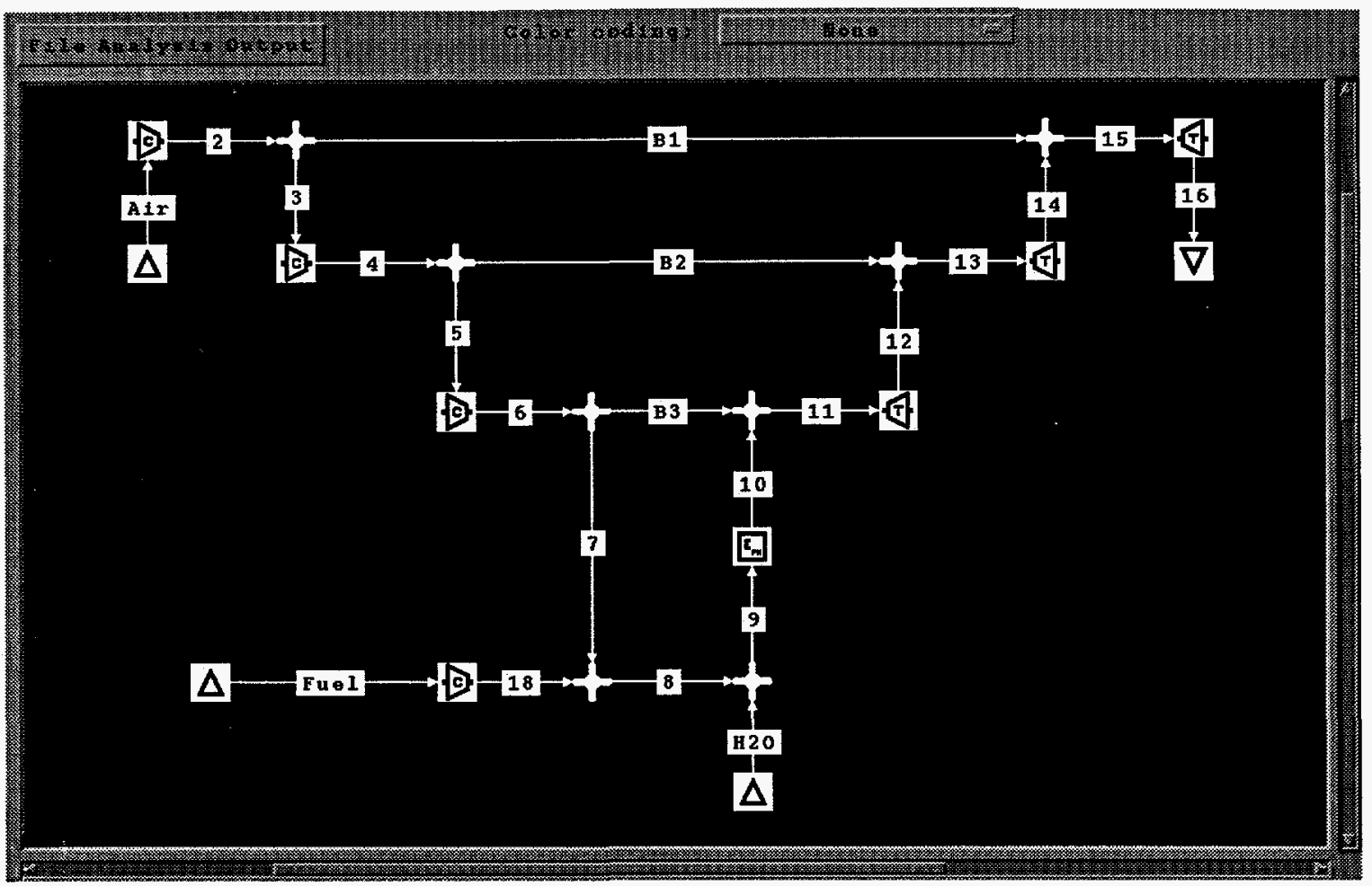

Figure 5. A completed cycle using multi-stage compression and expansion with bleed lines.

\section{Analysis}

Before TCAP can calculate the thermodynamic efficiency and emission levels for the cycle, the composition, flowrate, and thermodynamic state (temperature, pressure, enthalpy, entropy) of every fluid stream in the cycle must be known. Some of the properties will be specified by the user. TCAP will derive the others by using known relationships between properties. These relationships include (1) thermodynamic equations of state and (2) component behavior equations. Thermodynamic equations of state define the relationship between properties of an individual fluid stream, whereas component behavior equations define the relationship between properties of different fluid streams, namely, the fluid streams connected to the component. Component behavior equations also describe relationships between work and heat transfers and the fluid properties.

The equations of state used by TCAP are defined by the Chemkin ${ }^{1}$ library of thermodynamic subroutines. An example of a Chemkin subroutine is one that returns the specific enthalpy of a fluid, given its composition, temperature, and pressure. If the latter three properties have been specified by the user (or been previously calculated), TCAP will calculate the enthalpy of the fluid. 
The behavior of a component is defined by equations that relate the properties of the inlet and outlet fluid streams and the energy transfer of the work and heat connections. For example, a turbine's behavior is described in part by the following equations:

$$
\begin{aligned}
& \dot{m}_{\text {inlet }}=\dot{m}_{\text {outlet }} \\
& p_{\text {inlet }}=p_{\text {outlet }} \cdot r^{n}
\end{aligned}
$$

where $\dot{m}$ is the mass flowrate, $p$ is the fluid pressure, $r$ is the pressure ratio per stage, $n$ is the number of stages, and inlet and outlet refer to the inlet and outlet fluid streams. Equation (1) is a continuity equation, stating that no fluid is lost or created within the turbine. Equation (2) states the relationship between the inlet and outlet fluid pressures based on turbine parameters. If the inlet flowrate has been specified by the user (or has been previously calculated), then TCAP will calculate the outlet flowrate (and viceversa). Similarly, if one of the fluid pressures is known, TCAP will calculate the other, provided the turbine parameters have been defined.

Some of the component behaviors involve more complex relationships. An equilibrator component brings a fluid to an equilibrium state. TP-Equilibrators bring the fluid to chemical equilibrium at constant temperature and pressure, while TP-Phase Equilibrators bring the fluid to a phase equilibrium (no chemical reaction) at constant temperature and pressure. All equilibrium calculations are performed with a Chemkin-based implementation of the Stanjan ${ }^{2}$ solver. The PFR component models a plug flow reactor with a specified residence time, while the PSR component models a perfectly stirred reactor, also with a specified residence time. The behavior equations of the PFR and PSR components are based on the Senkin ${ }^{3}$ code and the PSR $^{4}$ code respectively. Behavior equations for all components are listed in the Appendix.

Once the cycle is constructed and parameters have been specified, TCAP attempts to calculate thermodynamic properties for each fluid state in the cycle. There are two solution modes: direct and iterative.

In the direct solution mode, TCAP searches through the cycle for unspecified properties. When it finds one, TCAP calculates the value of the property if there is enough information to calculate it directly. This will be true if the property is the only unknown variable in an equation of state or behavior equation. The search and calculate procedure is repeated until all fluid states are defined and the solution is complete. The direct solution mode succeeds for many cycle configurations. However, some configurations, especially those with closed loops, cannot be solved in this fashion. In these cases, TCAP attempts the iterative solution mode.

In the iterative solution mode, equations of state and behavior equations are set up as a single system of simultaneous equations, where the unknown variables are the unspecified thermodynamic properties. If the cycle has been properly constructed, the number of equations will be equal to the number of unknown properties, and TCAP will 
solve for the properties using an iterative solution algorithm named TJMAR $1^{5}$. This solution mode is computationally more intensive than the direct mode, but is also more powerful.

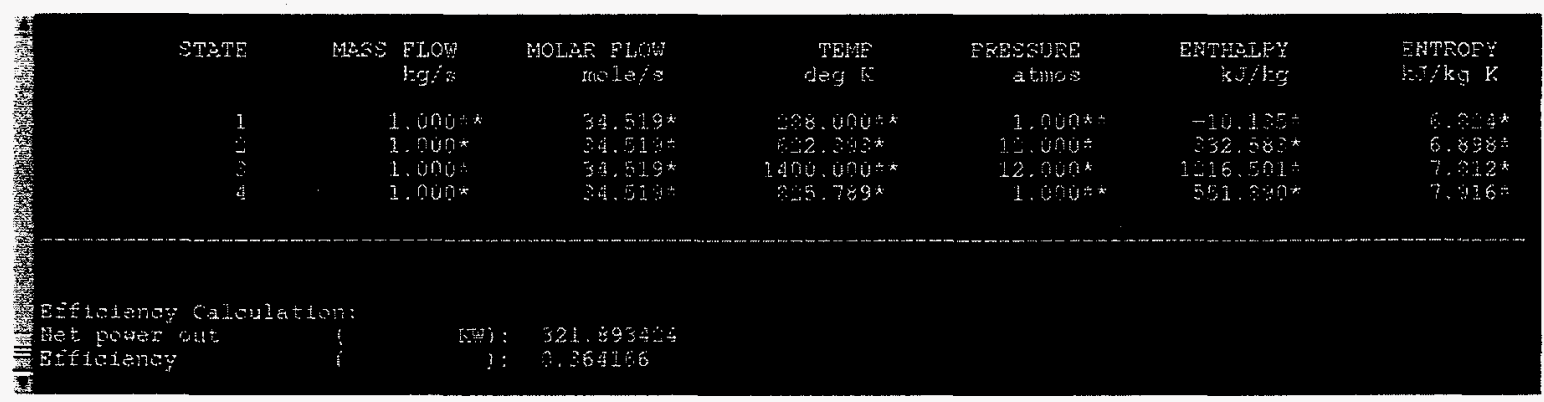

Figure 6. Solution printout for the basic air cycle.

When the cycle solution is complete, TCAP prints out a table of all fluid properties. The printout for the basic cycle of Figure 4 is displayed in Figure 6. The program keeps track of the origin of each of the property values. Those that were specified by the user are marked with a double asterisk $(* *)$. Calculated values are marked with a single asterisk (*). Value origins are also identified on the cycle drawing. In Figure 7, the color of each fluid connection corresponds to the origin of the fluid temperature. Green denotes a user specified temperature, yellow denotes a calculated value. If any fluid temperature were still unknown, it would be colored red.

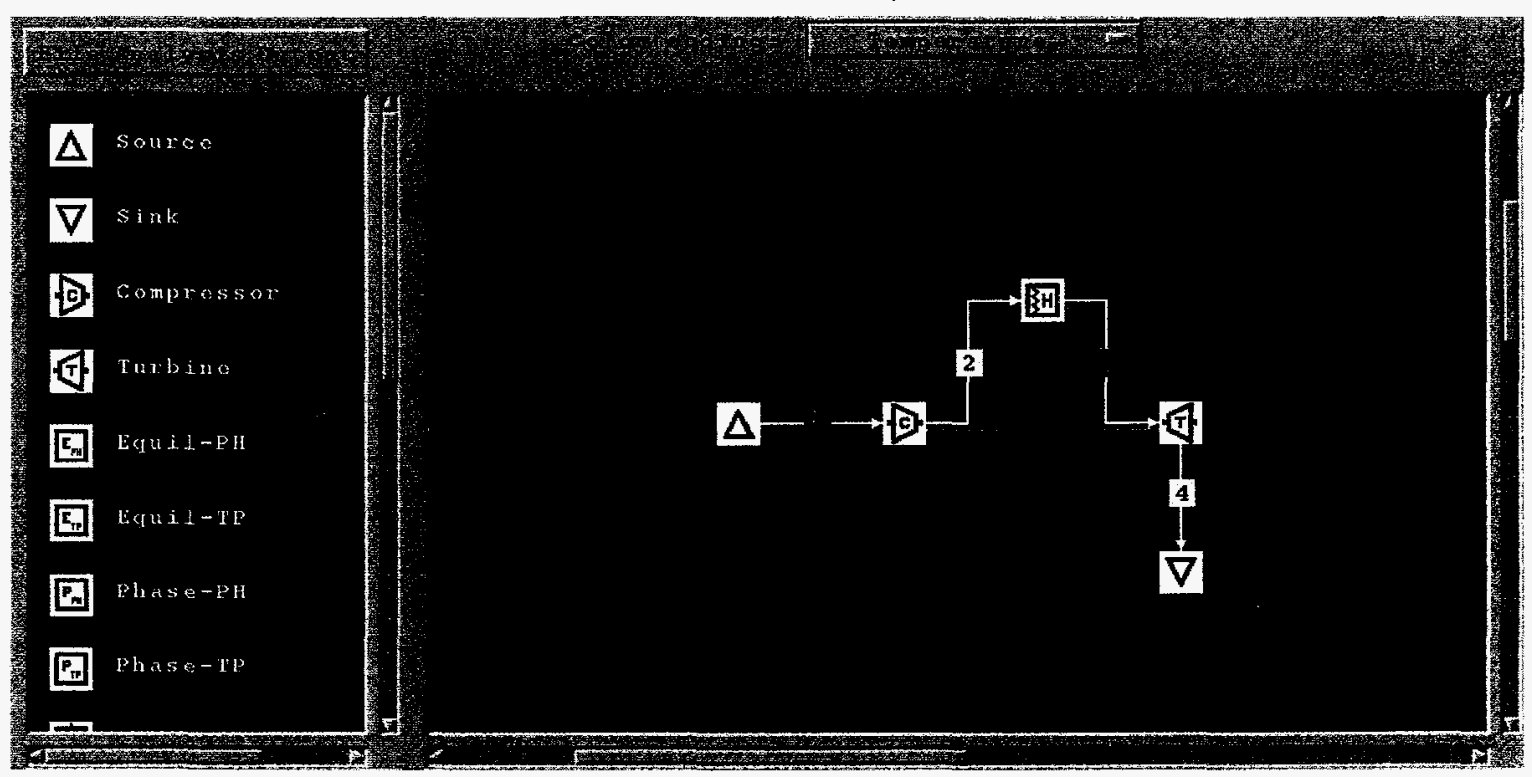

Figure 7. The basic cycle with fluid color-coding based on the origin of the temperature value.

The thermodynamic efficiency is calculated as the net available turbine work divided by the net energy input to the cycle. Energy input includes both sensible heat (which flows 
into heaters and reformers) and the latent heat of the working fluid. Emission levels are determined by analyzing fluid streams that flow into sinks, as these represent fluids that flow out of the cycle into the surrounding environment. From the flowrates and compositions of these streams, the emission level can be calculated for any chemical species of interest.

\section{Conclusion}

The TCAP software was developed to support the analysis needs of the CAGT project. With TCAP, a user can quickly construct thermodynamic cycles using a graphical user interface. No programming skills are required. TCAP can solve for the thermodynamic states of the fluid throughout the cycle, and from this data the thermodynamic efficiency and emission levels can be determined for the cycle.

The modeling of components in TCAP is done on a fairly simple and generic level. In particular, the components that are used to represent a combustion engine are not nearly as detailed as other models, both commercial ${ }^{6}$ and proprietary, that have been developed for specific makes of engines. These customized models often require dozens of input variables. Although TCAP cannot approach this level of detail, the CAGT Project analysts believed that TCAP would be sufficiently accurate for their comparative study of cycle configurations, and could serve as a common base-line analysis tool. 


\section{References}

${ }^{1}$ R. J. Kee, F. M. Rupley, and J. A. Miller, Chemkin-II: A Fortran Chemical Kinetics Package for the Analysis of Gas-Phase Chemical Kinetics, SAND89-8009B. Sandia National Laboratories, Livermore, California, November 1991.

${ }^{2}$ W. C. Reynolds, STANJAN. Department of Mechanical Engineering, Stanford University, Stanford, California, January 1986.

${ }^{3}$ A. E. Lutz, R. J. Kee, and J. A. Miller, SENKIN: A Fortran Program for Predicting Homogeneous Gas Phase Chemical Kinetics With Sensitivity Analysis, SAND87-8248. Sandia National Laboratories, Livermore, California, December 1989.

${ }^{4}$ P. Glarborg, R. J. Kee, J. F. Grcar, and J. A. Miller, PSR: A Fortran Program for Modeling Well-Stirred Reactors, SAND86-8209. Sandia National Laboratories, Livermore, California, February 1992.

${ }^{5}$ T. H. Jefferson, TJMARI - A Fortran Subroutine for Nonlinear Least Squares Parameter Estimation, SLL-73-0305. Sandia National Laboratories, Livermore, California, March 1974.

${ }^{6}$ ENTER Software, Inc., GATE/CYCLE. Menlo Park, California. 



\section{Appendix}

\section{Component Behavior}

Nomenclature used throughout this appendix:

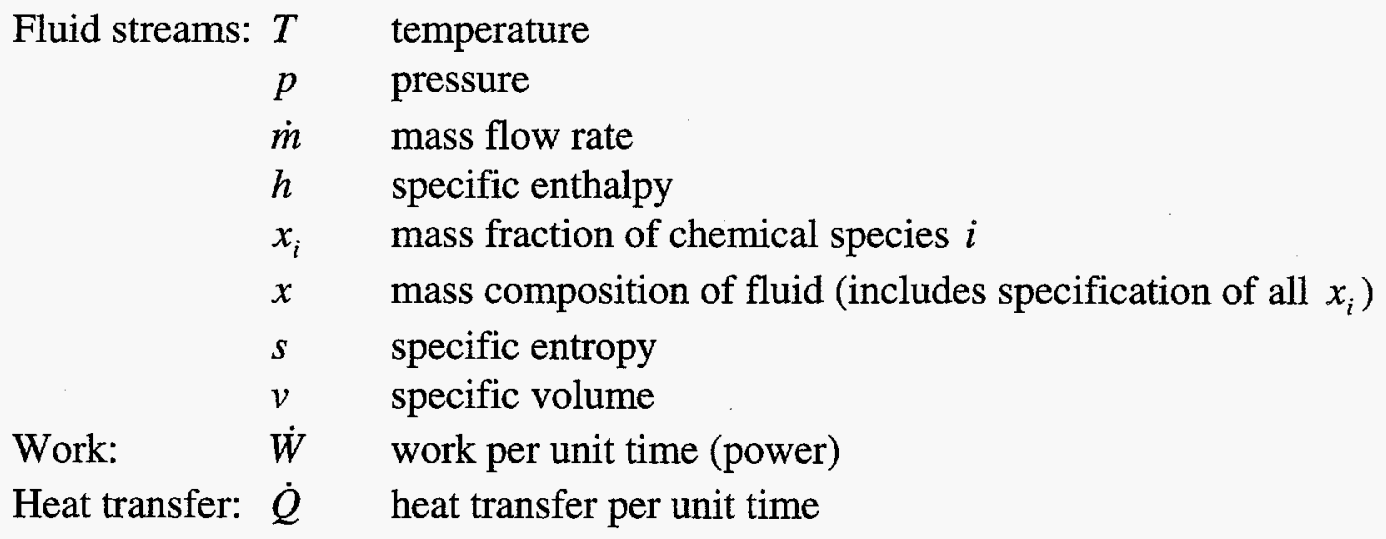

Numerical subscripts refer to the labeled streams in the component diagram. 


\section{Turbine}

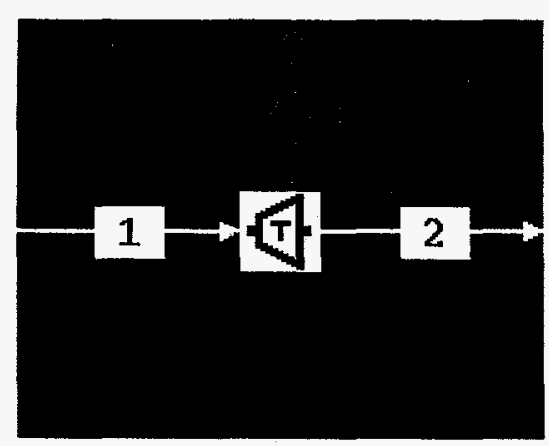

\section{Parameters}

$$
\begin{array}{ll}
n & \text { number of stages } \\
r & \text { pressure ratio per stage (input/output) } \\
\eta & \text { isentropic efficiency for each stage }
\end{array}
$$

Behavior

$$
\begin{aligned}
& \dot{m}_{1}=\dot{m}_{2} \\
& x_{i 1}=x_{i 2} \\
& p_{1}=r^{n} \cdot p_{2} \\
& \dot{W}=\dot{m}_{1} \cdot\left(h_{1}-h_{2}\right)
\end{aligned}
$$

For each stage:

$$
\begin{aligned}
& p_{\text {in }}=r \cdot p_{\text {out }} \\
& \eta=\frac{\left(h_{\text {in }}-h_{\text {out }}\right)}{\left(h_{\text {in }}-h_{s}\right)} \text { where } h_{s} \text { is the specific enthalpy of the fluid at }\left(s_{\text {in }}, p_{\text {out }}\right) .
\end{aligned}
$$

Fluid 1 is the "in" fluid for stage 1 . Fluid 2 is the "out" fluid for stage $n$.

\section{Notes}

The fluid's chemical composition is kept frozen as the fluid flows through the turbine. However, the fluid's phase composition (liquid/gas) is allowed to change as the pressure decreases. At the turbine outlet the fluid will be in phase equilibrium, but might not be in chemical equilibrium. 


\section{Compressor}

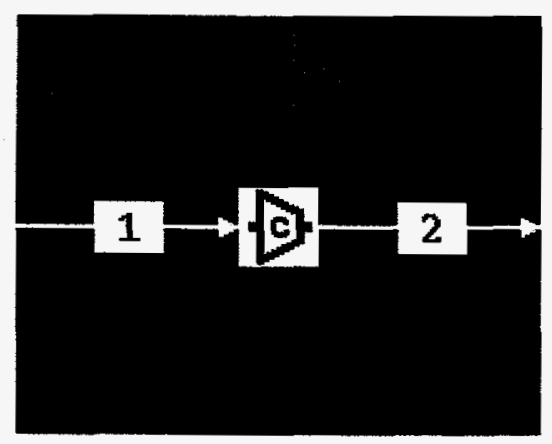

Parameters

$n \quad$ number of stages

$r \quad$ pressure ratio per stage (output/input)

$\eta \quad$ isentropic efficiency for each stage

Behavior

$$
\begin{aligned}
& \dot{m}_{1}=\dot{m}_{2} \\
& x_{i 1}=x_{i 2} \\
& p_{2}=r^{n} \cdot p_{1} \\
& \dot{W}=\dot{m}_{1} \cdot\left(h_{2}-h_{1}\right)
\end{aligned}
$$

For each stage:

$$
\begin{aligned}
& p_{\text {out }}=r \cdot p_{\text {in }} \\
& \eta=\frac{\left(h_{s}-h_{\text {in }}\right)}{\left(h_{\text {out }}-h_{\text {in }}\right)} \text { where } h_{s} \text { is the specific enthalpy of the fluid at }\left(s_{\text {in }}, p_{\text {out }}\right) .
\end{aligned}
$$

Fluid 1 is the "in" fluid for stage 1. Fluid 2 is the "out" fluid for stage $n$.

\section{Notes}

The fluid's chemical composition is kept frozen as the fluid flows through the compressor. However, the fluid's phase composition (liquid/gas) is allowed to change as the pressure increases. At the compressor outlet the fluid will be in phase equilibrium, but might not be in chemical equilibrium. 


\section{Heater}

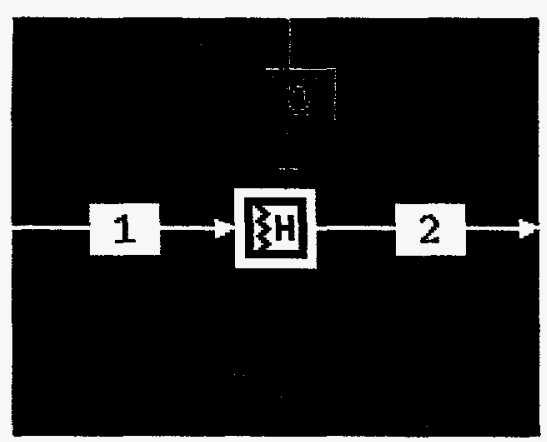

Behavior

$$
\begin{aligned}
& \dot{m}_{1}=\dot{m}_{2} \\
& x_{i 1}=x_{i 2} \\
& p_{1}=p_{2} \\
& \dot{Q}=\dot{m}_{1} \cdot\left(h_{2}-h_{1}\right)
\end{aligned}
$$

\section{Notes}

The fluid's chemical composition is kept frozen as the fluid flows through the heater.

However, the fluid's phase composition (liquid/gas) is allowed to change as the enthalpy increases. At the heater outlet the fluid will be in phase equilibrium, but might not be in chemical equilibrium.

A heater connected to a cooler with a heat connection forms a heat exchanger. 


\section{Cooler}

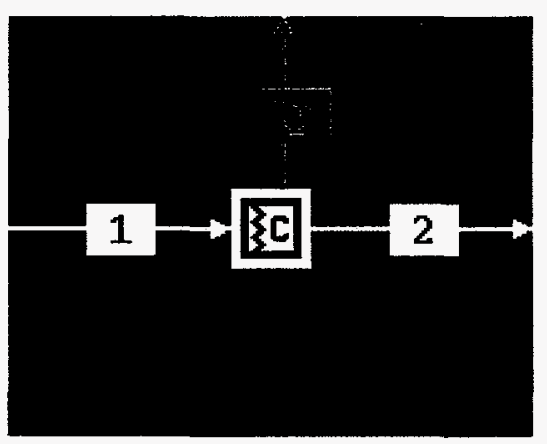

Behavior

$$
\begin{aligned}
& \dot{m}_{1}=\dot{m}_{2} \\
& x_{i 1}=x_{i 2} \\
& p_{1}=p_{2} \\
& \dot{Q}=\dot{m}_{1} \cdot\left(h_{1}-h_{2}\right)
\end{aligned}
$$

\section{Notes}

The fluid's chemical composition is kept frozen as the fluid flows through the cooler. However, the fluid's phase composition (liquid/gas) is allowed to change as the enthalpy decreases. At the cooler outlet the fluid will be in phase equilibrium, but might not be in chemical equilibrium.

A cooler connected to a heater with a heat connection forms a heat exchanger. 


\section{Perfectly Stirred Reactor (PSR)}

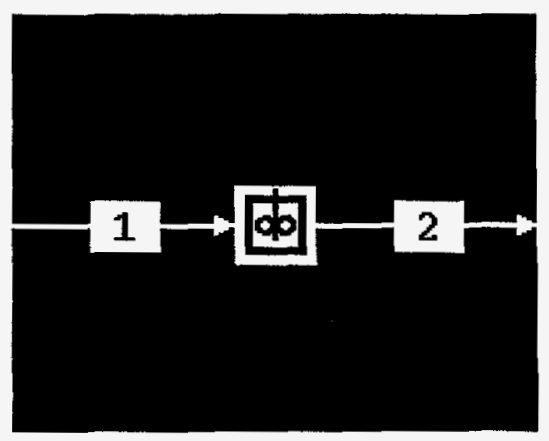

Parameters

$t \quad$ residence time

Behavior

$$
\begin{aligned}
& \dot{m}_{1}=\dot{m}_{2} \\
& p_{1}=p_{2} \\
& x_{2}, T_{2}=\operatorname{PSR}\left(x_{1}, p_{1}, T_{1}, t\right)
\end{aligned}
$$

\section{Notes}

The function PSR predicts the steady-state temperature and species composition for a perfectly stirred reactor. It is based on a FORTRAN program named PSR. ${ }^{\mathrm{a}}$ 


\section{Plug Flow Reactor (PFR)}

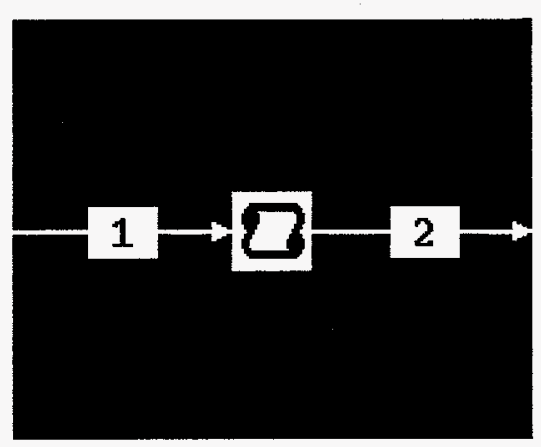

\section{Parameters}

$t \quad$ residence time

Behavior

$$
\begin{aligned}
& \dot{m}_{1}=\dot{m}_{2} \\
& p_{1}=p_{2} \\
& x_{2}, T_{2}=\operatorname{PFR}\left(x_{1}, p_{1}, T_{1}, t\right)
\end{aligned}
$$

\section{Notes}

The function PFR predicts the steady-state temperature and species composition for a plug flow reactor. It is based on a FORTRAN program named Senkin. ${ }^{b}$ 


\section{Reformer}

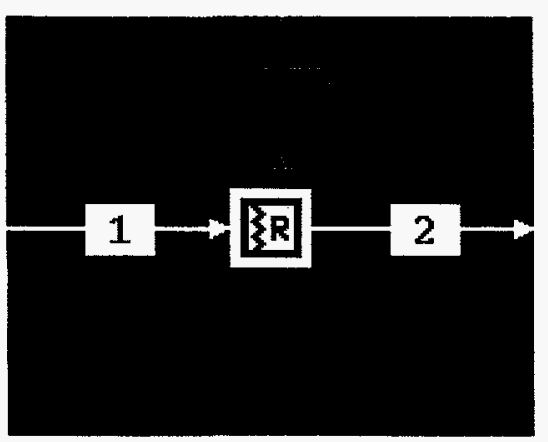

\section{Parameters}

$\Delta T \quad$ equilibrium approach temperature differential

Behavior

$$
\begin{aligned}
& \dot{m}_{1}=\dot{m}_{2} \\
& p_{1}=p_{2} \\
& \dot{Q}=\dot{m}_{1} \cdot\left(h_{2}-h_{1}\right) \\
& x_{2}=E Q U I L_{-} T P\left(x_{1}, p_{2},\left(T_{2}-\Delta T\right)\right)
\end{aligned}
$$

\section{Notes}

The function EQUIL_TP predicts the chemical equilibrium composition for a specified temperature and pressure, given an initial composition. It is based on a Chemkin implementation of the Stanjan ${ }^{c}$ solver.

The reaction that takes place in a reformer does not always proceed to completion (chemical equilibrium at $T_{2}$ ). Therefore, the outlet composition is approximated as the chemical equilibrium state at $\left(T_{2}-\Delta T\right)$ rather than at $T_{2}$. 


\section{P-H Equilibrator}

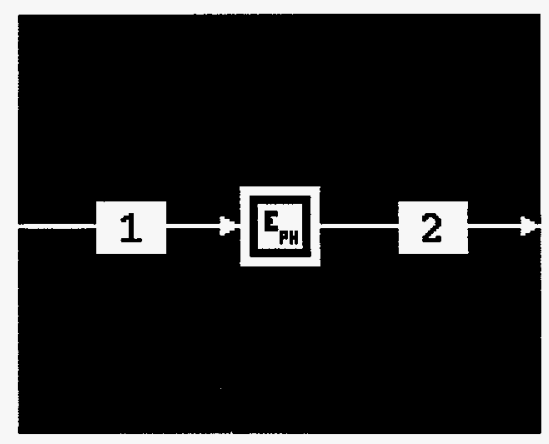

Behavior

$$
\begin{aligned}
& \dot{m}_{1}=\dot{m}_{2} \\
& p_{1}=p_{2} \\
& h_{1}=h_{2} \\
& x_{2}=\text { EQUIL_PH }\left(x_{1}, p_{2}, h_{2}\right)
\end{aligned}
$$

\section{Notes}

The P-H Equilibrator brings the fluid to chemical equilibrium at constant pressure and enthalpy.

The function $E Q U I L_{-} P H$ predicts the chemical equilibrium composition for a specified enthalpy and pressure, given an initial composition. It is based on a Chemkin implementation of the Stanjan ${ }^{c}$ solver. 


\section{T-P Equilibrator}

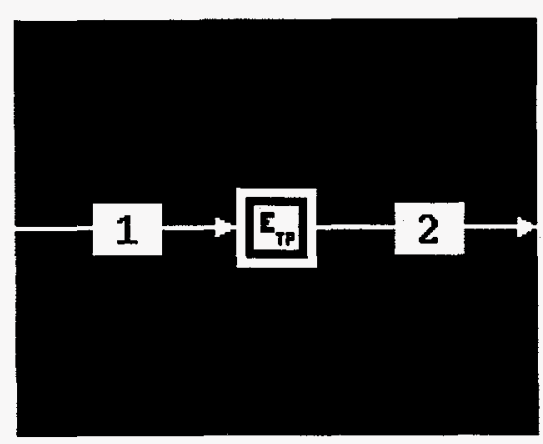

Behavior

$$
\begin{aligned}
& \dot{m}_{1}=\dot{m}_{2} \\
& p_{1}=p_{2} \\
& T_{1}=T_{2} \\
& x_{2}=\text { EQUIL_TP }\left(x_{1}, p_{2}, T_{2}\right)
\end{aligned}
$$

\section{Notes}

The T-P Equilibrator brings the fluid to chemical equilibrium at constant temperature and pressure.

The function EQUIL_TP predicts the chemical equilibrium composition for a specified temperature and pressure, given an initial composition. It is based on a Chemkin implementation of the Stanjan ${ }^{\mathrm{c}}$ solver. 


\section{P-H Phase Equilibrator}

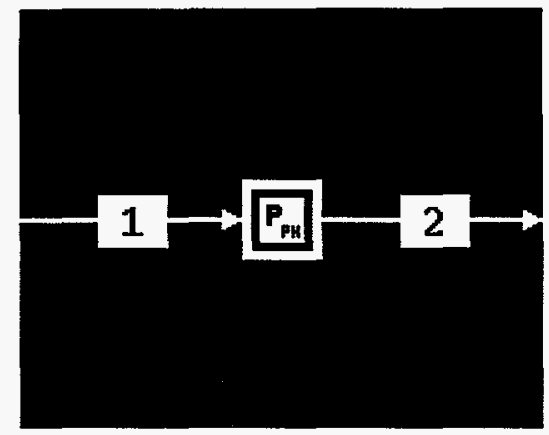

Behavior

$$
\begin{aligned}
& \dot{m}_{1}=\dot{m}_{2} \\
& p_{1}=p_{2} \\
& h_{1}=h_{2} \\
& x_{2}=\text { PHASE_PH }\left(x_{1}, p_{2}, h_{2}\right)
\end{aligned}
$$

\section{Notes}

The P-H Phase Equilibrator brings the fluid to phase equilibrium at constant pressure and enthalpy.

The function $P H A S E_{-} P H$ predicts the phase equilibrium composition for a specified enthalpy and pressure, given an initial composition. It is based on a Chemkin implementation of the Stanjan ${ }^{\mathrm{c}}$ solver. 


\section{T-P Phase Equilibrator}

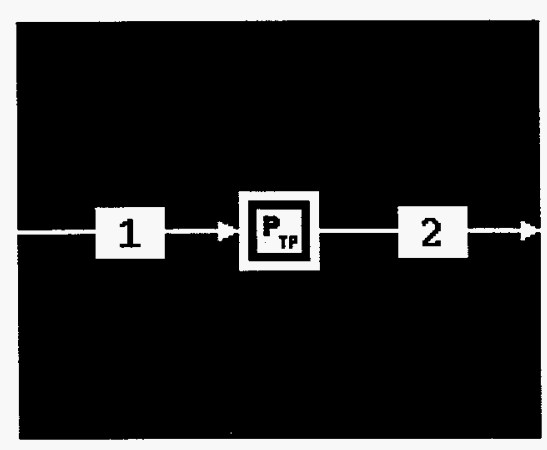

Behavior

$$
\begin{aligned}
& \dot{m}_{1}=\dot{m}_{2} \\
& p_{1}=p_{2} \\
& T_{1}=T_{2} \\
& x_{2}=\text { PHASE_TP }\left(x_{1}, p_{2}, T_{2}\right)
\end{aligned}
$$

\section{Notes}

The T-P Phase Equilibrator brings the fluid to phase equilibrium at constant temperature and pressure.

The function $P H A S E \_T P$ predicts the phase equilibrium composition for a specified temperature and pressure, given an initial composition. It is based on a Chemkin implementation of the Stanjan ${ }^{c}$ solver. 


\section{Pump}

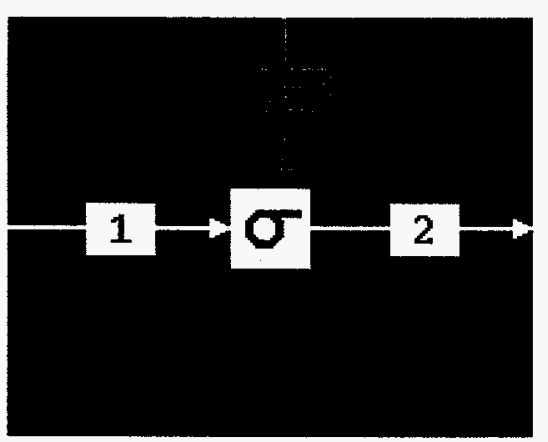

\section{Parameters}

$r$ pressure ratio (output/input)

$\eta \quad$ efficiency

\section{Behavior}

$$
\begin{aligned}
& \dot{m}_{1}=\dot{m}_{2} \\
& x_{i 1}=x_{i 2} \\
& p_{2}=r \cdot p_{1} \\
& \dot{W}=\dot{m}_{1} \cdot\left(h_{2}-h_{1}\right) \\
& \eta=\frac{v \cdot\left(p_{2}-p_{1}\right)}{\left(h_{2}-h_{1}\right)}
\end{aligned}
$$

\section{Notes}

The fluid's chemical composition is kept frozen as the fluid flows through the pump. However, the fluid's phase composition (liquid/gas) is allowed to change as the pressure increases. At the pump outlet the fluid will be in phase equilibrium, but might not be in chemical equilibrium. 


\section{Valve}

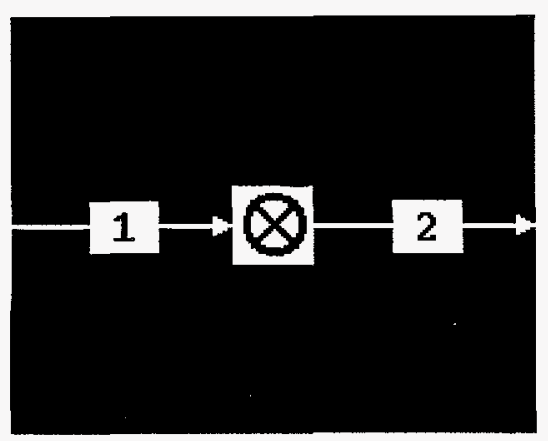

Parameters

$r \quad$ pressure ratio (input/output)

Behavior

$$
\begin{aligned}
& \dot{m}_{1}=\dot{m}_{2} \\
& x_{i 1}=x_{i 2} \\
& h_{1}=h_{2} \\
& p_{1}=r \cdot p_{2}
\end{aligned}
$$

\section{Notes}

The valve pressure reduction is isenthalpic.

The fluid's chemical composition is kept frozen as the fluid flows through the valve. However, the fluid's phase composition (liquid/gas) is allowed to change as the pressure decreases. At the valve outlet the fluid will be in phase equilibrium, but might not be in chemical equilibrium. 


\section{Mixer (Junction)}

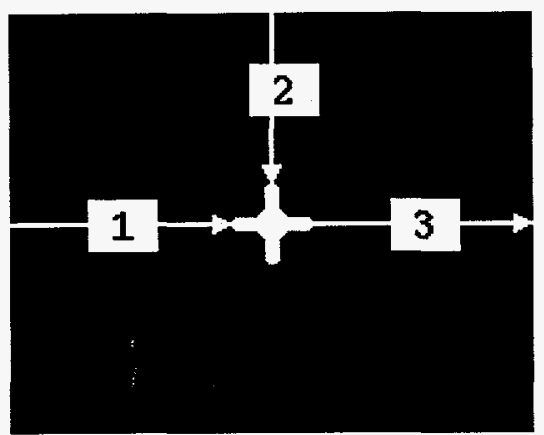

Behavior

$$
\begin{aligned}
& \dot{m}_{1}+\dot{m}_{2}=\dot{m}_{3} \\
& \dot{m}_{1} \cdot x_{i 1}+\dot{m}_{2} \cdot x_{i 2}=\dot{m}_{3} \cdot x_{i 3} \\
& p_{3}=\min \left(p_{1}, p_{2}\right) \\
& \dot{m}_{1} \cdot h_{1}+\dot{m}_{2} \cdot h_{2}=\dot{m}_{3} \cdot h_{3}
\end{aligned}
$$

\section{Notes}

The mixing process is adiabatic.

\section{Splitter (Junction)}

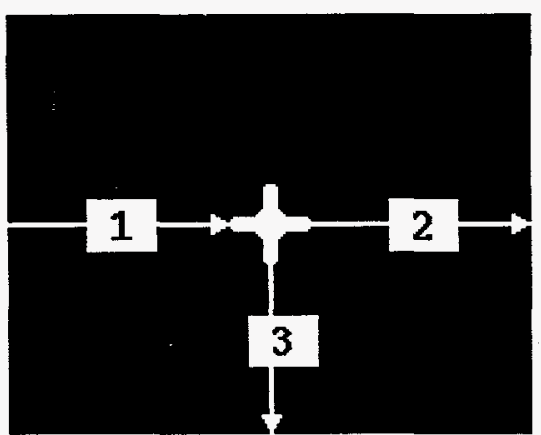

Behavior

$$
\begin{aligned}
& \dot{m}_{1}=\dot{m}_{2}+\dot{m}_{3} \\
& x_{i 1}=x_{i 2}=x_{i 3} \\
& p_{1}=p_{2}=p_{3} \\
& h_{1}=h_{2}=h_{3}
\end{aligned}
$$

Notes

The flowrate for at least one of the output fluid streams must be specified. 


\section{Separator}

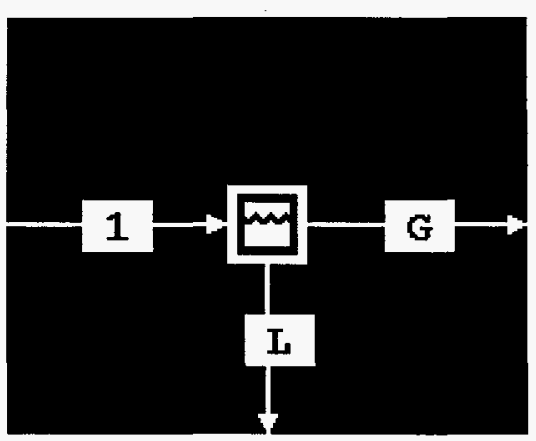

Behavior

$$
\begin{aligned}
& \dot{m}_{1}=\dot{m}_{2}+\dot{m}_{3} \\
& p_{1}=p_{2}=p_{3} \\
& T_{1}=T_{2}=T_{3}
\end{aligned}
$$

Notes

The separator component separates the incoming fluid into liquid and gas streams. The first outgoing connection created for the separator will be the gas stream, the second will the liquid stream. 


\section{Source}

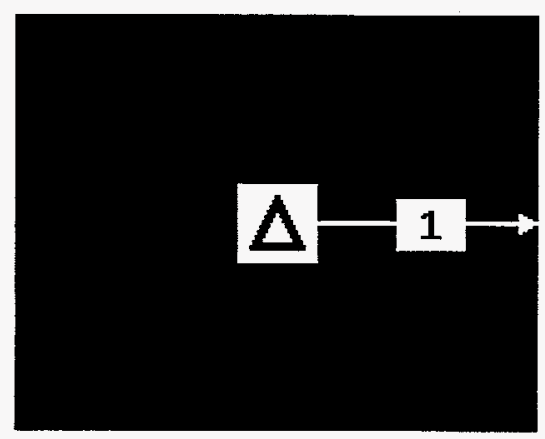

Notes

The source component represents a fluid source external to the cycle.

\section{Sink}

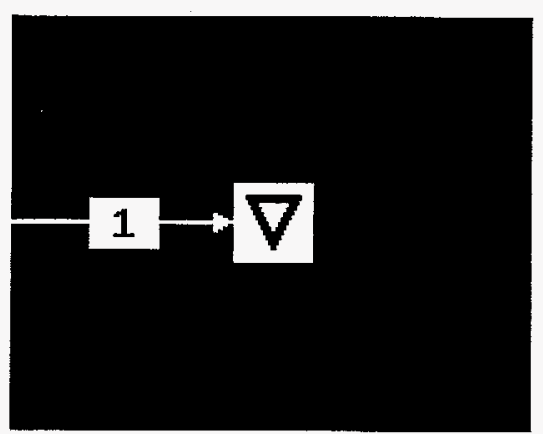

\section{Notes}

The sink component represents a fluid sink external to the cycle. 


\section{Turbine - Frozen Composition}

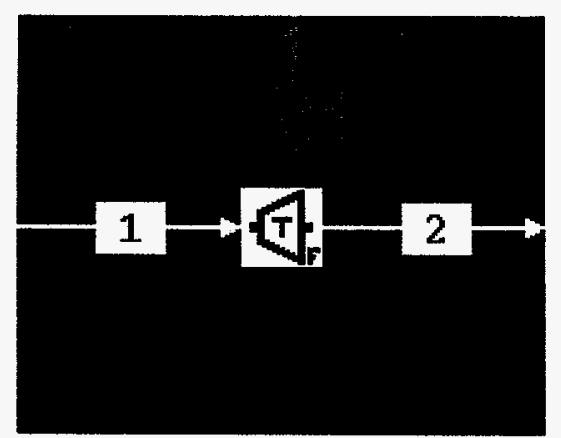

\section{Parameters}

$n \quad$ number of stages

$r \quad$ pressure ratio per stage (input/output)

$\eta \quad$ isentropic efficiency for each stage

\section{Behavior}

$$
\begin{aligned}
& \dot{m}_{1}=\dot{m}_{2} \\
& x_{i 1}=x_{i 2} \\
& p_{1}=r^{n} \cdot p_{2} \\
& \dot{W}=\dot{m}_{1} \cdot\left(h_{1}-h_{2}\right)
\end{aligned}
$$

For each stage:

$$
\begin{aligned}
& p_{\text {in }}=r \cdot p_{\text {out }} \\
& \eta=\frac{\left(h_{\text {in }}-h_{\text {out }}\right)}{\left(h_{\text {in }}-h_{s}\right)} \text { where } h_{s} \text { is the specific enthalpy of the fluid at }\left(s_{\text {in }}, p_{\text {out }}\right) .
\end{aligned}
$$

Fluid 1 is the "in" fluid for stage 1 . Fluid 2 is the "out" fluid for stage n.

\section{Notes}

The fluid's chemical composition and phase composition are kept frozen as fluid flows through the turbine. At the turbine outlet the fluid might not be in chemical or phase equilibrium. 


\section{Compressor - Frozen Composition}

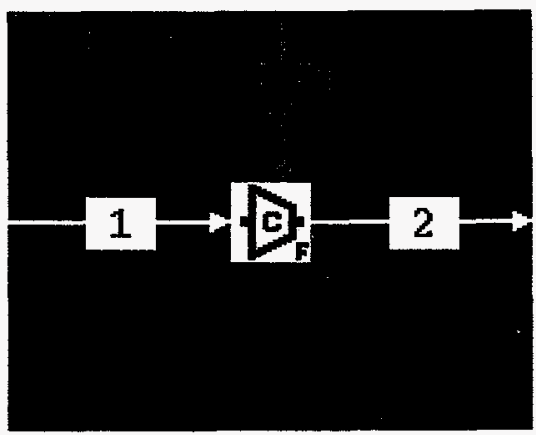

\section{Parameters}

$n \quad$ number of stages

$r \quad$ pressure ratio per stage (output/input)

$\eta \quad$ isentropic efficiency for each stage

\section{Behavior}

$$
\begin{aligned}
& \dot{m}_{1}=\dot{m}_{2} \\
& x_{i 1}=x_{i 2} \\
& p_{2}=r^{n} \cdot p_{1} \\
& \dot{W}=\dot{m}_{1} \cdot\left(h_{2}-h_{1}\right)
\end{aligned}
$$

For each stage:

$$
\begin{aligned}
& p_{\text {out }}=r \cdot p_{\text {in }} \\
& \eta=\frac{\left(h_{s}-h_{\text {in }}\right)}{\left(h_{\text {out }}-h_{\text {in }}\right)} \text { where } h_{s} \text { is the specific enthalpy of the fluid at }\left(s_{\text {in }}, p_{\text {out }}\right) .
\end{aligned}
$$

Fluid 1 is the "in" fluid for stage 1. Fluid 2 is the "out" fluid for stage $n$.

\section{Notes}

The fluid's chemical composition and phase composition are kept frozen as fluid flows through the compressor. At the compressor outlet the fluid might not be in chemical or phase equilibrium. 


\section{Pump - Frozen Composition}

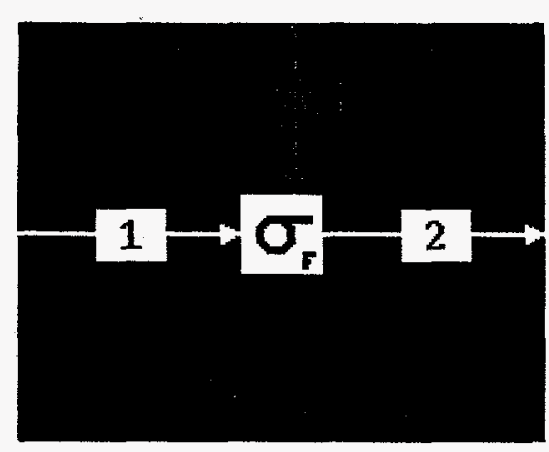

Parameters

$r \quad$ pressure ratio (output/input)

$\eta \quad$ efficiency

Behavior

$$
\begin{aligned}
& \dot{m}_{1}=\dot{m}_{2} \\
& x_{i 1}=x_{i 2} \\
& p_{2}=r \cdot p_{1} \\
& \dot{W}=\dot{m}_{1} \cdot\left(h_{2}-h_{1}\right) \\
& \eta=\frac{v \cdot\left(p_{2}-p_{1}\right)}{\left(h_{2}-h_{1}\right)}
\end{aligned}
$$

\section{Notes}

The fluid's chemical composition and phase composition are kept frozen as fluid flows through the pump. At the pump outlet the fluid might not be in chemical or phase equilibrium. 
a P. Glarborg, R. J. Kee, J. F. Grcar, and J. A. Miller, PSR: A Fortran Program for Modeling Well-Stirred Reactors. SAND86-8209, Sandia National Laboratories, Livermore, California, February 1992.

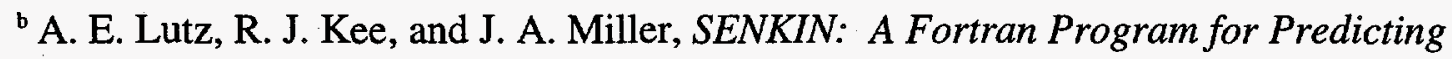
Homogeneous Gas Phase Chemical Kinetics With Sensitivity Analysis. SAND87-8248. Sandia National Laboratories, Livermore, California, December 1989.

' W. C. Reynolds, STANJAN. Department of Mechanical Engineering, Stanford University, Stanford, California, January 1986. 


\section{UNLIMITED RELEASE}

\section{INITIAL DISTRIBUTION:}

1 MS 9001 T. O. Hunter, 8000;

Attn: J. B. Wright, 2200

M. E. John, 8100

L. A. West, 8200

W. J. McLean, 8300

R. C. Wayne, 8400

P. N. Smith, 8500

T. M. Dyer, 8700

P. E. Brewer, 8800

D. L. Crawford 8900

$1 \quad$ MS 9042

MS 9042

A. E. Lutz, 8345

E. Meeks, 8345

MS 9201

L. D. Brandt 8112

P. K. Falcone, 8114

MS 9201

A. S. Yoshimura, 8112

$10 \quad$ MS 9021

Technical Communications Department, 8815/for OSTI

$1 \quad$ MS 9021

Technical Communications Department, 8815/Technical Library, MS 0899, 4414

4 MS 0899 Technical Library, 4414

3 MS 9018 Central Technical Files, 8940-2 